Office of Energy Research

Office of Basic Energy Sciences

Carbon Dioxide Research Division

GC

Washington, D.C. 20545

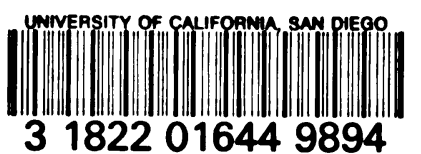

\title{
Carbonate Chemistry of the Weddell Sea
}

by

Chen-Tung A. Chen

College of Oceanography

Oregon State University

Corvallis, OR 97331

Under Contract No. DE-AT06-81EV10611 